\title{
Biomassa, atividade microbiana e FMA em rotação cultural milho/ feijão-de-corda utilizando-se águas salinas ${ }^{1}$
}

\author{
Biomass, microbial activity and AMF in crop rotation system of maize/ cowpea using \\ saline water
}

\author{
Maria Eloneide de Jesus Bezerra², Claudivan Feitosa de Lacerda ${ }^{3}$, Geocleber Gomes de Sousa ${ }^{4 *}$, Vânia Felipe \\ Freire Gomes ${ }^{5}$ e Paulo Furtado Mendes Filho ${ }^{5}$
}

\begin{abstract}
Resumo - O objetivo deste trabalho foi avaliar a influência da irrigação com água de alta e baixa salinidade sobre variáveis microbiológicas do solo em área submetida à rotação de cultura entre milho (Zea Mays L.) e feijão-de-corda (Vigna unguiculata L.). A área destinada ao experimento foi dividida em duas subáreas, sendo realizados quatro cultivos: dois cultivos irrigados na estação seca e dois de sequeiro na estação chuvosa. $\mathrm{O}$ estudo foi conduzido em campo, utilizando-se o delineamento em blocos ao acaso, com cinco repetições. Nos cultivos irrigados foram usadas água com as seguintes condutividades elétricas (CEa): 0,8;2,2; 3,6 e 5,0 dS m ${ }^{-1}$. Os cultivos de sequeiro foram realizados nas mesmas parcelas que foram cultivadas na estação seca, as quais permaneceram demarcadas e identificadas. No início e ao final de cada cultivo, foram coletadas amostras em duas subáreas na região radicular das plantas, no terço médio da fileira central de cada parcela. $\mathrm{O}$ aumento da salinidade da água de irrigação promoveu aumento do número total de esporos de fungos micorrízicos arbusculares FMA e reduziu a respiração basal do solo, o carbono da biomassa e o coefíciente metabólico microbiano $\left(\mathrm{qCO}_{2}\right)$, principalmente na área cultivada com feijão-de-corda. $\mathrm{O}$ gênero Glomus respondeu por mais de $70 \%$ dos esporos totais encontrados, sendo que essa percentagem aumentou nos tratamentos com maior salinidade nos cultivos da estação seca. Os dados não evidenciaram qualquer efeito negativo da salinidade residual sobre as variáveis microbiológicas avaliadas, em função da irrigação com água salina durante os cultivos da estação seca.
\end{abstract}

Palavras-chave - Estresse salino. Zea mays L. Vigna unguiculata L. Microrganismos.

\begin{abstract}
This work carred out the influence of irrigation with water of high and low salinity on soil microbial variables in area under the crop rotation between maize (Zea mays L.) and cowpea (Vigna unguiculata L.). The area for the experiment was divided into two sub areas being made four crops, two crops irrigated in the dry season and two dry in the rainy season. The study was conducted under field conditions using a randomized block design with five replications. In irrigated crops were used the following water with electrical conductivity $(\mathrm{ECw}): 0.8 ; 2.2 ; 3.6$ and $5.0 \mathrm{dS} \mathrm{m}^{-1}$. The rainfed crops were conducted on the same plots that were cultivated during the dry season, which remained demarcated and identified. At the beginning and end of each crop were collected samples in two subareas in the region of root system plant, in the middle third of the central row of each plot. Increasing of salinity in irrigation water led to increase in the total number of spores and reduced soil basal respiration, biomass carbon and microbial metabolic coefficient $\left(\mathrm{qCO}_{2}\right)$, mainly in the area cultivated with cowpea. The genus Glomus accounted for more than $70 \%$ of total spores found, and this percentage increased in treatments with high salinity in dry season crops. The data reveal no residual negative effect of salinity on the microbial variables assessed in function irrigation with saline water during the dry season crops.
\end{abstract}

Key words - Salt stress. Zea mays L. Vigna unguiculata L. Microrganisms.

\footnotetext{
* Autor para correspondência

'Recebido para publicação em 14/08/2009; aprovado em 27/09/2010

Parte da monografia do primeiro autor apresentada ao CCA/Universidade Federal do Ceará

2Programa de Pós-Graduação em Solos e Nutrição de Plantas, CCA/UFC, Fortaleza-CE, Brasil, eloneidebezerra@yahoo.com.br ${ }^{3}$ Departamento de Engenharia Agrícola, CCA/UFC, Fortaleza-CE, Brasil, cfeitosa@ufc.br

${ }^{4}$ Programa de Pós-Graduação em Engenharia Agrícola, CCA/UFC, Caixa Postal 12. 168, Fortaleza-CE, Brasil, 60.455 970, sousasolosgeo@hotmail.com

${ }_{5}^{5}$ Departamento de Ciências do Solo, CCA/UFC, Fortaleza-CE, Brasil, vaniafreire@ufc.br, mendes@ufc.br
} 


\section{Introdução}

A crescente necessidade de se aumentar a produção de alimentos se constitui em um sério desafio científico-tecnológico e tem requerido a expansão das áreas cultivadas. Entretanto, essa busca não leva em conta apenas a incorporação das áreas agrícolas consideradas adequadas ao cultivo, mas também o aproveitamento de áreas degradadas, como os solos afetados por sais, e águas consideradas de qualidade inferior, a exemplo das águas com elevados teores de sais (BANARD et al., 2010; GARCIA et al., 2008).

A irrigação é uma das tecnologias aplicadas na agricultura que mais tem contribuído para o aumento na produção de alimentos (BERNADO, 2008). No entanto, a qualidade da água apresenta restrições à agricultura irrigada e pode resultar em obstáculo ao desenvolvimento das culturas, além de acelerar a degradação física do solo (SILVA et al., 2005).

Em locais de clima árido e semiárido é comum a ocorrência de solos com elevadas concentrações de sais, sendo que alguns deles se apresentam salinizados independentes da ação do homem, ou seja, são salinos por natureza. No entanto, o estudo e o manejo de microrganismos edáficos tolerantes a ambientes adversos é atualmente uma alternativa complementar a ser usada na agricultura, sendo que estudos indicam que a associação simbiótica de plantas com fungos micorrízicos arbusculares FMA promovem maior tolerância das plantas aos vários tipos de estresse (SAINT-ETIENE et al., 2006; SILVA JÚNIOR et al., 2009).

A colonização com micorriza arbuscular é relatada como responsável por aumentar o crescimento de várias espécies de plantas sob condições de salinidade, fato que tem sido demonstrado em algumas espécies (JUNIPER; ABBOTT 2006; YANO-MELO et al., 2003). No entanto, a salinidade e outros estresses além de afetarem o desenvolvimento das plantas, podem também afetar a atividade dos microrganismos e suas interações com as raízes das plantas (YUAN et al., 2007). Nesse contexto, torna-se cada vez mais importante a integração dos estudos sobre as características dos solos e suas relações com os microrganismos.

O objetivo deste trabalho foi avaliar a influência da irrigação com água de alta e baixa salinidade sobre o número de esporos de fungos micorrízicos arbusculares, a respiração basal do solo e a atividade microbiana do solo em áreas submetidas à rotação de cultura entre milho e feijão-de-corda.

\section{Material e métodos}

O experimento foi instalado no campo, em Argissolo Vermelho Amarelo (SANTOS et al., 2006), localizado no Laboratório de Hidráulica e Irrigação da Universidade Federal do Ceará, Campus do Pici, em Fortaleza $\left(3^{\circ} 45^{\prime} \mathrm{S}\right.$; $38^{\circ} 33^{\prime} \mathrm{W}$ e altitude de $19 \mathrm{~m}$ em relação ao nível do mar). A área destinada ao experimento foi dividida em duas subáreas, sendo realizados dois cultivos irrigados na estação seca (setembro a dezembro de 2007) e dois cultivos de sequeiro na estação chuvosa (janeiro a abril de 2008) utilizando milho (Zea mays L.) Híbrido AG 1051 e feijão-de-corda [Vigna unguiculata (L.) Walp.] cultivar EPACE 10, em sistema de rotação. A subárea 1 foi cultivada primeiro com o milho, no período seco, e posteriormente com o feijão-de-corda, no período chuvoso. Já a subárea 2 foi semeada inicialmente com o feijão-de-corda (estação seca) seguido do cultivo do milho (estação chuvosa).

O experimento teve duração total de sete meses. Alguns atributos químicos do solo antes da instalação dos tratamentos nas subáreas 1 e 2 e a distribuição decendial das precipitações encontram-se na Tabela 1 e Figura 1, respectivamente.

Tabela 1 - Alguns atributos químicos do solo antes da aplicação dos tratamentos, na camada de 0 a $0,20 \mathrm{~m}$

\begin{tabular}{|c|c|c|c|c|c|c|c|c|}
\hline \multicolumn{9}{|c|}{ Características } \\
\hline M.O & $\mathrm{Ca}^{2+}$ & $\mathrm{Mg}^{2+}$ & $\mathrm{Na}^{+}$ & SB & $\mathrm{P}$ & $\mathrm{K}^{+}$ & $\mathrm{pH}$ & $\mathrm{CEa}$ \\
\hline $\mathrm{g} \mathrm{dm}^{-3}$ & $------\cdot$ & $-----\mathrm{cm}$ & $-3----\cdot$ & ------ & $\mathrm{Mg} \mathrm{dm}^{-3}$ & $\mathrm{cmol}_{\mathrm{c}} \mathrm{dm}^{-3}$ & & $\mathrm{dS} \mathrm{m} \mathrm{m}^{-1}$ \\
\hline \multicolumn{9}{|c|}{ Antes do plantio do milho } \\
\hline 8,48 & 1,5 & 1,1 & 0,26 & 3 & 10 & 0,11 & 6,3 & 0,42 \\
\hline \multicolumn{9}{|c|}{ Antes do plantio do feijão-de-corda } \\
\hline 8,99 & 0,8 & 0,7 & 0,19 & 1,8 & 6 & 0,1 & 5,3 & 0,4 \\
\hline
\end{tabular}

M.O - Matéria orgânica; SB - soma de bases $\left(\mathrm{Ca}^{2+}+\mathrm{Mg}^{2+}+\mathrm{Na}^{+}+\mathrm{K}^{+}\right)$; o pH foi medido em extrato aquoso $(1: 2,5)$ 


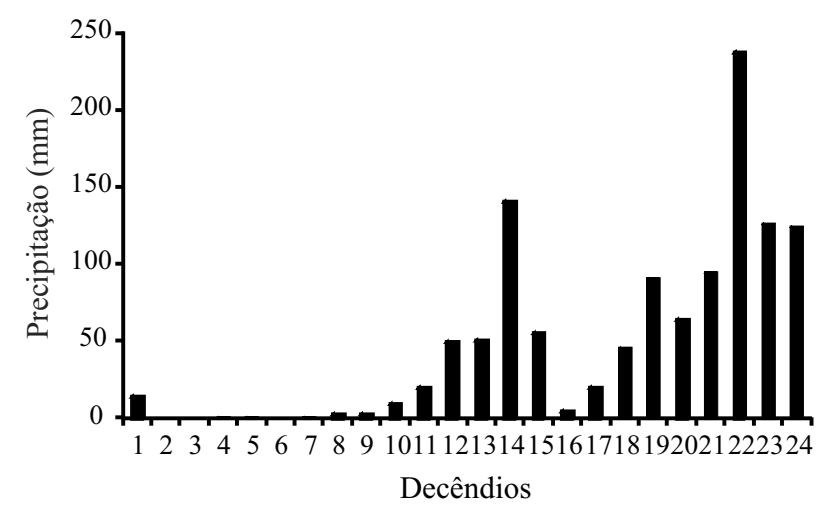

Figura 1 - Precipitação dos decêndios referentes ao período entre Setembro/2007 a Abril/2008

$\mathrm{Na}$ estação seca, após o estabelecimento das culturas, cerca de 8 dias após a semeadura do milho e 15 dias depois do plantio do feijão-de-corda, as plantas passaram a ser irrigadas com águas salinas apresentando quatro diferentes concentrações de sais. Nos cultivos irrigados foram usadas água com condutividade elétrica $(\mathrm{CEa})$ de 0,8 (água do poço), 2,2; 3,6 e 5,0 dS m $\mathrm{m}^{-1}$ constituindo, assim, os tratamentos $1 ; 2 ; 3$ e 4 , respectivamente. Para o preparo das soluções salinas, adicionaram-se os seguintes sais: $\mathrm{NaCl}, \mathrm{CaCl}_{2} \cdot 2 \mathrm{H}_{2} \mathrm{O}$ e $\mathrm{MgCl}_{2} \cdot 6 \mathrm{H}_{2} \mathrm{O}$ dissolvidos na água do poço, na proporção de $7: 2: 1$, conforme Rhoades et al. (2000).

As lâminas de irrigação foram determinadas com base nos valores da ETo (obtidas através do Tanque Classe A) e pelos coeficientes da cultura $\left(\mathrm{K}_{\mathrm{c}}\right)$, correspondentes aos diferentes estádios fenológicos (DOORENBOS; KASSAM, 1994). O volume distribuído em cada sulco era controlado por meio de um hidrômetro. Às lâminas de água aplicadas foram adicionadas frações de lixiviação (15\%) para prevenir o acúmulo excessivo de sais no solo próximo à zona radicular (AYERS; WESTCOT, 1999).

A adubação foi realizada com base na análise de solo, seguindo a recomendação de Fernandes (1993), utilizando-se $\mathrm{N}, \mathrm{P}_{2} \mathrm{O}_{5}$ e $\mathrm{K}_{2} \mathrm{O}$, aplicando-se as doses de 60; 30 e $30 \mathrm{~kg} \mathrm{ha}^{-1}$ para o milho e 20; 60 e $30 \mathrm{~kg} \mathrm{ha}^{-1}$ para o feijão- de-corda, respectivamente. O delineamento experimental foi o de blocos ao acaso, com cinco repetições, totalizando 20 unidades experimentais em cada subárea.

Os cultivos na estação chuvosa, nas duas subáreas, foram realizados nas mesmas parcelas em que foram cultivadas anteriormente durante o período seco, sendo a semeadura realizada após as primeiras chuvas. Durante a estação chuvosa foram realizadas apenas duas irrigações suplementares com água do poço, durante um veranico que ocorreu no mês de fevereiro.

As amostras de solo foram coletadas antes da instalação do experimento, após os cultivos irrigados na estação seca e após os cultivos da estação chuvosa. A ocorrência de FMA no solo foi verificada através da extração de esporos pela técnica do peneiramento úmido, método descrito por Gerdermann e Nicolson (1963). A identificação dos gêneros de FMA existentes nas amostras de solo coletadas foi realizada com auxílio da chave de identificação de Schenk e Pérez (1990). Amostras do material peneirado foram examinadas com o auxilio de estereomicroscópio para verificação da presença de FMA.

A respiração basal do solo foi determinada pela quantidade de $\mathrm{CO}_{2}$ liberado num período de 8 dias de incubação. O carbono da biomassa microbiana (CBM) foi determinado pelo método descrito por Vance et al. (1987), utilizando-se para a eliminação dos microrganismos, forno de microondas por três minutos (ISLAM; WEIL, 1998). $\mathrm{O}$ fator de conversão usado para converter o fluxo de $\mathrm{C}$ para $\mathrm{C}$ da biomassa microbiana foi de 0,33 de acordo com Sparling e West (1988), para compensar as perdas de C em $\mathrm{CO}_{2}$ durante o armazenamento do substrato. O coeficiente metabólico microbiano $\left(\mathrm{qCO}_{2}\right)$ foi calculado pela relação entre a respiração basal do solo RBS $\left(\mu \mathrm{g} \mathrm{C}-\mathrm{CO}_{2} \mathrm{~h}^{-1}\right)$ por $\mathrm{mg}$ de carbono da biomassa microbiana (ANDERSON; DOMSCH, 1990).

Asamostras coletadas antes dese iniciaremas irrigações salinas serviram como referência da situação inicial da área em estudo, a qual se encontrava em pousio. Na Tabela 2 são apresentadas as médias de esporos de gêneros de FMA, a respiração basal e o carbono da biomassa microbiana nas duas subáreas, antes da instalação dos experimentos.

Tabela 2 - Número de esporos por gênero de FMA, respiração basal do solo (RBS) e carbono da biomassa microbiana (CBM) nas subáreas 1 e 2, antes da instalação dos experimentos*

\begin{tabular}{|c|c|c|c|c|c|c|}
\hline \multirow{2}{*}{ Subáreas } & Glomus & Gigáspora & Scutellospora & Paraglomus & RBS & CBM \\
\hline & \multicolumn{4}{|c|}{ 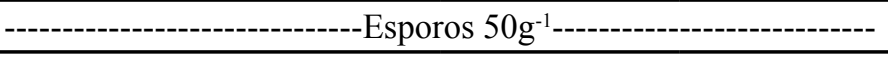 } & $\mathrm{mg} \mathrm{CO}_{2} 50 \mathrm{~g}^{-1}$ & $\mathrm{~g} \mathrm{~kg}^{-1}$ \\
\hline 1 & 26,8 & 1,8 & 4,5 & 6,8 & 9,1 & 0,09 \\
\hline 2 & 9,5 & 0,8 & 2,5 & 4,3 & 10,0 & 0,06 \\
\hline
\end{tabular}

* Os valores são médias de três sub-amostras 
Os dados dos cultivos irrigados na estação seca, de cada subárea, foram submetidos às análises de variância e de regressão, utilizando-se o programa computacional SAEG/UFV (RIBEIRO JÚNIOR, 2001). A análise de variância foi também empregada para avaliar os efeitos residuais da salinidade durante os cultivos na estação chuvosa. Na análise de variância dos dados de contagem de esporos utilizou-se a transformação $\log (x+2)$, em função da ocorrência de zeros.

\section{Resultados e discussão}

A irrigação com águas salinas influenciou o total de esporos de FMA $(\mathrm{p}<0,05)$, sendo o efeito linear crescente na subárea 2 , cultivada com feijão-de-corda (FIG. 2A). Na subárea 1, cultivada com milho, também ocorreu um aumento no número de esporos de FMA, porém os dados não se ajustaram a nenhum modelo matemático. Observa-se, também, que a irrigação durante a estação seca promoveu um incremento na ocorrência de FMA, visto que o número de esporos aumentou em relação aos valores observados antes dos cultivos (TAB. 2), nas duas subáreas.

$\mathrm{O}$ aumento da salinidade da água de irrigação resultou em aumento no número de esporos do gênero Glomus $(\mathrm{p}<0,05)$. Nota-se que as tendências dos dados dos esporos totais (FIG. 2A) e do gênero Glomus (FIG. 2B) são bem semelhantes, o que se deve ao fato desse gênero ter representado acima de $70 \%$ dos esporos encontrados em todas as amostragens, sendo que essa participação aumentou nos tratamentos com maior salinidade. $\mathrm{Na}$ área cultivada com feijão-de-corda a percentagem de esporos de Glomus variou de 80 a 93,7\%, entre os tratamentos com menor e maior nível de salinidade da água de irrigação. Na área cultivada com milho essa percentagem variou de 70 a $78 \%$, respectivamente. Antes dos cultivos irrigados, a participação percentual de esporos de Glomus, em relação ao total, era de 67 e 55\% nas subáreas 1 e 2, respectivamente.

A presença de esporos dos demais gêneros não foi influenciada pela salinidade da água de irrigação $(\mathrm{p}>0,05)$. Os valores médios encontrados para Gigáspora, Scutellospora e Paraglomus foram, respectivamente, 2,$1 ; 2,2$ e 7,9 esporos $50 \mathrm{~g}^{-1}$ de solo, na subárea 1 (cultivada com milho), valores que não diferiram muito daqueles observados antes da instalação do experimento (TAB. 2). Na subárea 2 (cultivada com feijão-de-corda) os valores foram 0,6; 0,9 e 5,5 esporos $50 \mathrm{~g}^{-1}$ de solo, respectivamente. Observa-se que os valores na subárea 1 permaneceram superiores aos da subárea 2, refletindo os valores existentes antes da instalação dos experimentos.

De forma geral, sob condições adversas ou não, é comum a maior ocorrência do gênero Glomus, o que pode ser devido também a uma grande diversidade de espécies
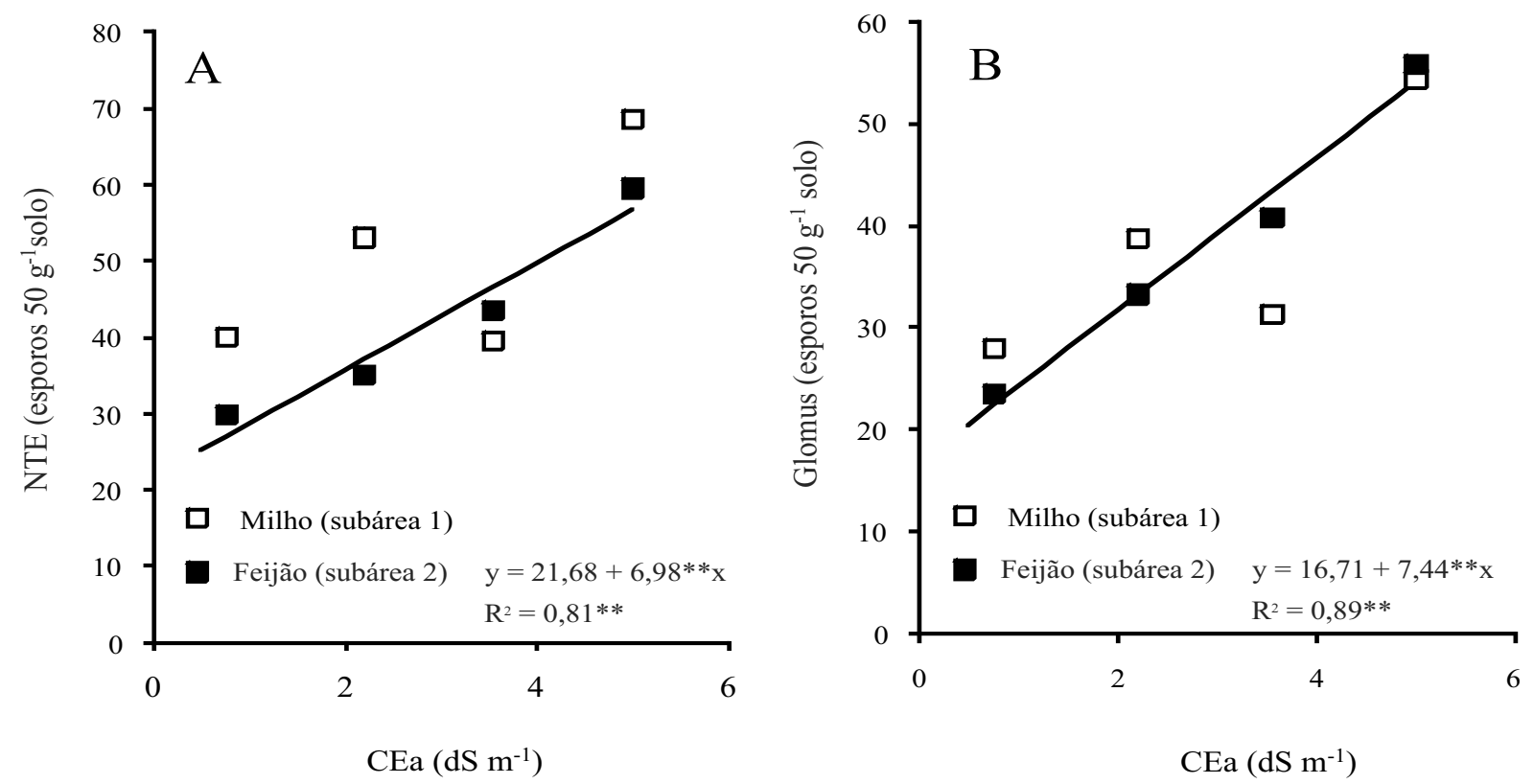

Figura 2 - Número total de esporos - NTE (A) de FMA e do gênero Glomus (B) em amostras de solo coletadas nas subáreas 1 (milho) e 2 (feijão-de-corda) após os cultivos irrigados com água salina. ** significativo a $1 \%$ 
pertencentes a este grupo (MOREIRA; SIQUEIRA, 2006). Em solos salinos, Wilde et al. (2009) encontraram cerca de $80 \%$ de esporos do gênero Glomus. Os resultados do presente estudo também coincidem com os relatos por Juniper e Abbott (1993), que concluíram que as espécies de fungos mais comuns em solos salinos são pertencentes ao gênero Glomus.

Apesar de ter sido observado aumento no número de esporos (FIG. 2), isso não significa necessariamente a ocorrência de maior colonização das plantas de milho e feijão-de-corda, visto que a germinação dos esporos e a colonização das raízes podem ser afetadas negativamente pela salinidade (JAHROMI et al., 2008; YANO - MELO et al., 2003). Saint-Etienne et al. (2006), estudando o fungo do gênero Pterocarpus officinarum (Jacq), verificaram que a percentagem de colonização de FMA diminui linearmente com o aumento da salinidade. Já Juniper e Abbott (2006), observaram que a adição de $\mathrm{NaCl}$ no solo inibiu a germinação de esporos e o comprimento de hifas/ esporos de FMA.

É importante salientar que na maioria dos estudos se utiliza o $\mathrm{NaCl}$ como agente estressante, o que difere do presente estudo em que foram utilizados proporções de sais de sódio, cálcio e magnésio. O uso de uma mistura de sais se aproxima das condições naturais de solos e águas afetados por sais, particularmente na região semiárida do Brasil (MEDEIROS, 1992), e os efeitos podem ser menos intensos do que aqueles observados com a utilização apenas de $\mathrm{NaCl}$, tanto sobre a planta como sobre as interações planta-microrganismos. De acordo com Juniper e Abbott (2006), a taxa de germinação máxima de FMA e a quantificação de esporos também podem depender do tipo de sal.

O aumento da salinidade da água de irrigação influenciou tanto a respiração basal do solo $(\mathrm{p}<0,05)$ como o carbono da biomassa microbiana $(\mathrm{p}<0,05)$, sendo que as respostas diferiram entre as duas subáreas. A salinidade de até $3,0 \mathrm{dS} \mathrm{m}^{-1}$ praticamente não afetou a respiração basal do solo nas duas subáreas (FIG. 3A), porém acima desse valor se observou aumento na RBS na área cultivada com milho e redução na área cultivada com feijão-de-corda. Por outro lado, o aumento da salinidade da água de irrigação até valores próximos de 3,6 dS m ${ }^{-1}$ resultou em incrementos na biomassa microbiana nas duas subáreas (FIG. 3B), porém no maior nível de salinidade verificou-se redução na área cultivada com feijão-de-corda e manutenção dos valores na área cultivada com milho.

Pereira et al. (2004), avaliando a respiração basal do solo irrigado com rejeito salino e cultivado com Atriplex nummularia, observaram que o solo cultivado por três anos não diferenciou-se em relação ao controle (área nativa). Silva Júnior et al. (2009) ao avaliarem os efeitos de níveis de salinidade sobre a atividade microbiana em Argissolo Amarelo incubado com diferentes adubos orgânicos, verificaram que a incorporação da matéria orgânica ao solo aumenta a quantidade de $\mathrm{C}-\mathrm{CO}_{2}$ mineralizado, mesmo em níveis elevados de salinidade. Já Wichern et al. (2006), estudando o impacto da salinidade na microbiota do solo, incubados em dois diferentes locais em Heringen - Alemanha, com três níveis de salinidade (0; 15 e $50 \mathrm{mg} \mathrm{NaCl} \mathrm{g}^{-1}$ de solo), verificaram que a salinidade teve efeito prejudicial aos microrganismos do
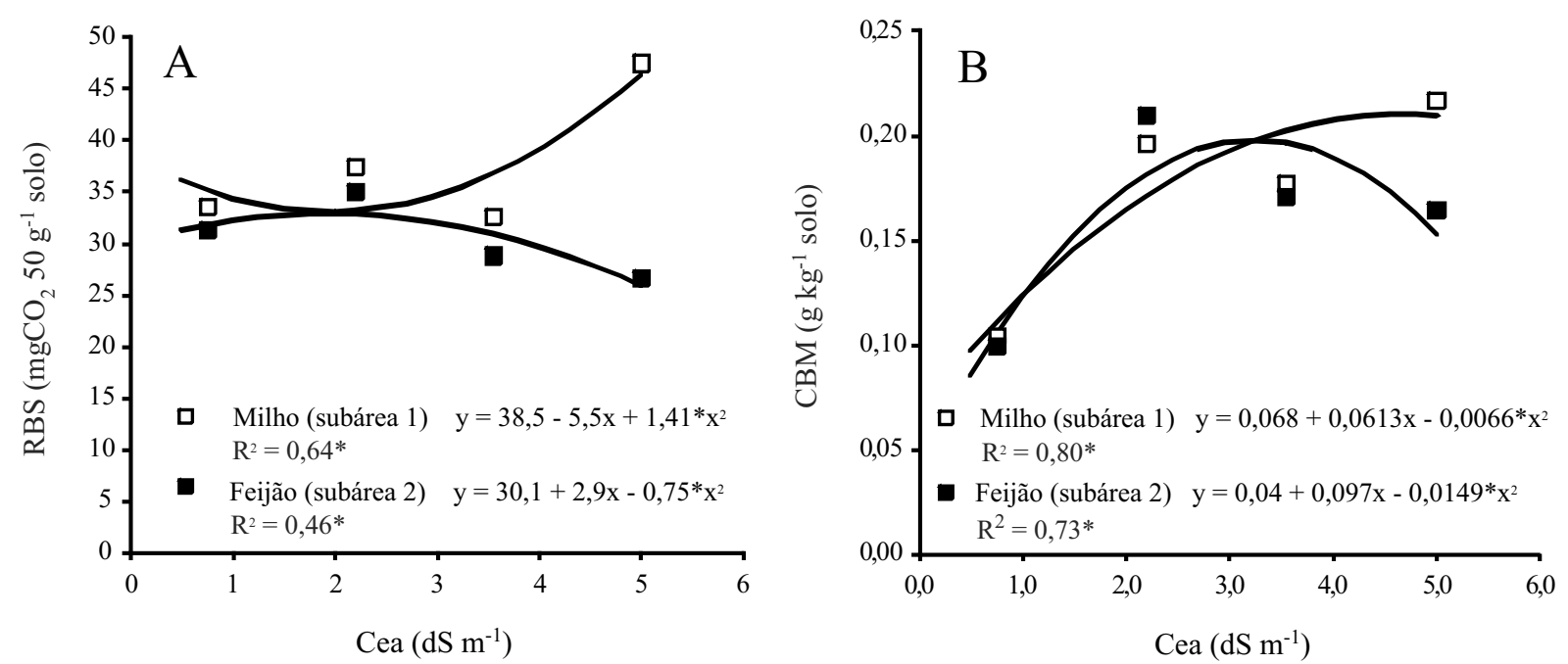

Figura 3 - Respiração basal do solo - RBS (A), acumulada nos 8 dias de incubação, e carbono da biomassa microbiana - CBM (B), em amostras de solo coletadas nas subáreas 1 (milho) e 2 (feijão-de-corda) após os cultivos irrigados com água salina. * significativo a $5 \%$ 
solo, resultando em diminuição da respiração basal. Esse último resultado é semelhante ao observado na subárea 2 , cultivada com feijão-de-corda, porém diferente daquele observado na subárea 1 , cultivada com milho, onde se verificou tendência de aumento nos níveis mais elevados de salinidade (FIG. 3A).

A salinidade da água de irrigação influenciou o quociente de $\mathrm{CO}_{2}\left(\mathrm{qCO}_{2}\right)$ na área cultivada com feijãode-corda $(\mathrm{p}<0,05)$, porém não foram observados efeitos significativos na área cultivada com milho ( $p>0,05)$. Observa-se, na Figura 4 que o aumento da salinidade reduziu o $\mathrm{qCO}_{2}$, com os menores valores sendo observado no tratamento com maior condutividade elétrica da água de irrigação, embora não tenha sido possível ajustar nenhum modelo matemático.

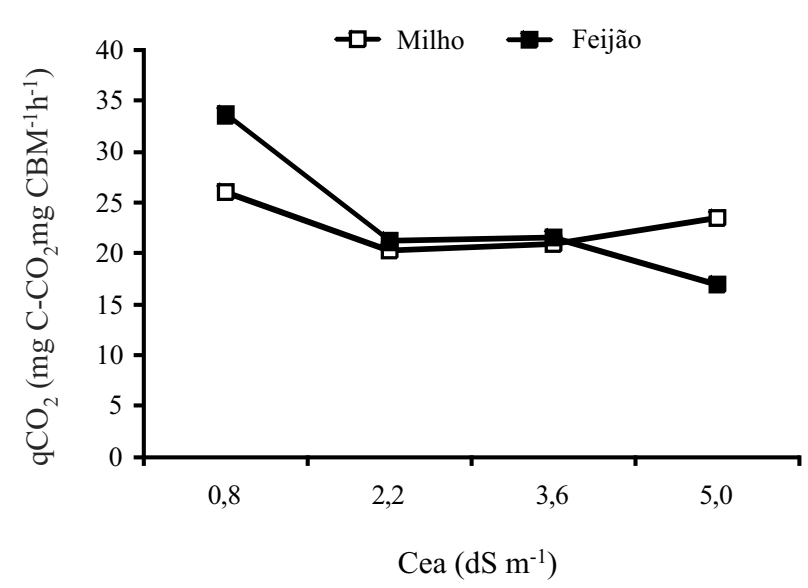

Figura 4 - Coeficiente metabólico microbiano $\left(\mathrm{qCO}_{2}\right)$ em amostras de solo coletadas nas subáreas 1 (milho) e 2 (feijão-decorda) após os cultivos irrigados com água salina

De acordo com Anderson (1994), o $\mathrm{qCO}_{2}$ pode ser aplicado para testar os efeitos do estresse sobre a comunidade microbiana, sendo que sob estresse pode ser detectada uma maior demanda de energia pelos microrganismos pelo aumento na evolução de $\mathrm{CO}_{2}$ por massa de células na unidade de tempo. Diferente dos resultados obtidos no presente estudo, Yuan et al. (2007) encontraram uma correlação positiva entre $\mathrm{qCO}_{2}$ e a salinidade do solo, o que segundo os autores reflete o resultado negativo da salinidade sobre os microrganismos do solo. Ainda de acordo com esses autores, os maiores valores de $\mathrm{qCO}_{2}$ nos níveis mais elevados de salinidade podem indicar baixa qualidade do substrato e baixa eficiência no funcionamento dos organismos. Além disso, comunidades de bactérias podem se tornar dominantes em ambientes salinos, as quais são menos eficientes do que os fungos na conversão de carbono do substrato em carbono celular, o que também justificaria o aumento no $\mathrm{qCO}_{2}$. Portanto, os resultados obtidos no presente estudo não estariam indicando a existência de estresse na comunidade microbiana do solo, podendo-se sugerir que os microrganismos na área cultivada com feijão-de-corda apresentaram-se mais eficiente sob condições salinas.

Os dados da Tabela 3 não evidenciam qualquer efeito negativo da salinidade residual, em função da irrigação com água salina durante os cultivos da estação seca. Nota-se que na subárea 1 (milho na estação seca seguido de feijão-de-corda na estação chuvosa) não foram observados efeitos significativos no número total de esporos (NTE), mas se observaram tendências de aumento na RBS e no CBM naqueles tratamentos que receberam irrigação com maiores níveis de sais no cultivo anterior. A manutenção de elevada taxa respiratória é indicativo de alta atividade biológica, e pode ser uma característica desejável, uma vez que pode significar transformação rápida de resíduos orgânicos em nutrientes disponíveis para as plantas (ISLAM; WEIL, 2000). Na subárea 2 (feijão-de-corda na estação seca seguido de milho na estação chuvosa) não foram observados efeitos sobre o NTE e RBS, sendo observado maiores valores no CBM nas parcelas anteriormente irrigadas com água com maior concentração de sais.

De modo geral, os valores médios de NTE, RBS e CBM foram menores após os cultivos da estação chuvosa (TAB. 3), em relação aos valores observados ao final dos cultivos na estação seca (FIG. 2 e 3). Caproni et al. (2003) estudando a diversidade de fungos micorrízicos arbusculares (FMA) em áreas em processo de revegetação na região de Porto Trombetas, PA, constataram que durante o período de sequeiro ocorreu maior esporulação de espécies de FMA que no período chuvoso. García e Mendoza (2007), estudando a associação simbiótica entre plantas e FMA em solo salino sódico, constataram que a percentagem de colonização de raiz apresenta-se diferente entre espécies de plantas e entre algumas estações do ano. Segundo esses autores, a diferença na colonização entre as espécies de plantas pode ser atribuída à interação entre a taxa de crescimento das raízes da planta e do fungo, nas diferentes estações do ano.

Os dados da Tabela 4 mostram que a aplicação de água salina no cultivo anterior teve pequena influência no número de esporos dos diferentes gêneros, com pequenas variações no número de esporos de Gigáspora e Scutellospora na subárea 1, e de Paraglomus na subárea 2. Nenhuma influência foi verificada no gênero Glomus, principal gênero de FMA encontrado nas áreas estudadas, porém os valores observados após a estação chuvosa (TAB. 4) foram bem inferiores aqueles no fỉnal da estação seca (FIG. 2B). 
Tabela 3 - Número total de esporos (NTE), Respiração basal do solo (RBS) e carbono da biomassa microbiana (CBM) em amostras de solo coletadas nas subáreas 1 e 2, após os cultivos do feijão-de-corda e do milho na estação chuvosa, respectivamente

\begin{tabular}{ccccccc}
\hline \multirow{2}{*}{$\mathrm{CEa}\left(\mathrm{dS} \mathrm{m}{ }^{-1}\right)$} & \multicolumn{2}{c}{ NTE esporos $50 \mathrm{~g}^{-1}$ solo } & \multicolumn{2}{c}{ RBS mg C-CO ${ }_{2} 50 \mathrm{~g}^{-1}$ de solo } & \multicolumn{2}{c}{ CBM g kg-1 de solo } \\
\cline { 2 - 7 } & Feijão & Milho & Feijão & Milho & Feijão & Milho \\
\hline $0,8 \#, \mathrm{a}$ & $16,0 \pm 3,3$ & $26,5 \pm 4,9$ & $15,5 \pm 0,2$ & $23,7 \pm 1,3$ & $0,06 \pm 0,00$ & $0,08 \pm 0,03$ \\
$0,8 \#, \mathrm{~b}$ & $18,5 \pm 4,7$ & $19,5 \pm 2,5$ & $14,3 \pm 0,5$ & $24,4 \pm 1,2$ & $0,11 \pm 0,01$ & $0,09 \pm 0,05$ \\
$0,8 \#, \mathrm{c}$ & $17,3 \pm 1,9$ & $24,5 \pm 3,3$ & $18,6 \pm 0,3$ & $22,9 \pm 1,0$ & $0,13 \pm 0,02$ & $0,12 \pm 0,01$ \\
$0,8 \#, \mathrm{~d}$ & $15,8 \pm 0,6$ & $22,3 \pm 1,0$ & $22,3 \pm 1,1$ & $21,3 \pm 2,8$ & $0,12 \pm 0,01$ & $0,15 \pm 0,01$ \\
Teste F & $\mathrm{ns}$ & $\mathrm{ns}$ & $* *$ & $\mathrm{~ns}$ & $* *$ & $*$ \\
CV $(\%)$ & 13,3 & 6,4 & 12,0 & 9,7 & 19,9 & 32,8 \\
\hline
\end{tabular}

*\# Irrigado com água de Tratamento $1\left(\mathrm{CEa}=0,8 \mathrm{dS} \mathrm{m} \mathrm{m}^{-1}\right)$ em caráter suplementar, nas parcelas anteriormente irrigadas com as águas de 0,$8 ; 2,2 ; 3,6 \mathrm{e}$ $5,0 \mathrm{dS} \mathrm{m}^{-1}(\mathrm{a}, \mathrm{b}, \mathrm{c}, \mathrm{d}$, respectivamente); médias \pm desvio padrão; $\mathrm{n}=5 ; \mathrm{ns}$ - não significativo; * significativo a $5 \%$; ** significativo a $1 \%$

Tabela 4 - Número de esporos de gêneros de FMA em amostras de solo coletadas nas subáreas 1 e 2, após os cultivos do feijão-decorda e milho na estação chuvosa, respectivamente

\begin{tabular}{|c|c|c|c|c|}
\hline \multirow[b]{2}{*}{$\mathrm{CEa}(\mathrm{dS} \mathrm{m}-1)$} & \multicolumn{4}{|c|}{ Esporos (número de esporos $50 \mathrm{~g}^{-1}$ solo) } \\
\hline & Glomus & Gigáspora & Scutellospora & Paraglomus \\
\hline & \multicolumn{4}{|c|}{ Feijão-de-corda (subárea 1) } \\
\hline $0,8^{\#, \mathrm{a}}$ & $12,3 \pm 5,3$ & $1,8 \pm 0,5$ & $0,8 \pm 0,9$ & $1,3 \pm 1,3$ \\
\hline $0,8^{\#, \mathrm{~b}}$ & $14,8 \pm 8,5$ & $1,0 \pm 0,0$ & $1,5 \pm 1,0$ & $1,3 \pm 0,9$ \\
\hline $0,8^{\#, \mathrm{c}}$ & $14,8 \pm 2,8$ & $1,0 \pm 0,0$ & $1,0 \pm 1,1$ & $0,5 \pm 0,6$ \\
\hline $0,8^{\#, \mathrm{~d}}$ & $9,3 \pm 0,9$ & $1,0 \pm 0,0$ & $3,3 \pm 0,5$ & $2,3 \pm 1,5$ \\
\hline Teste F & ns & $*$ & $*$ & ns \\
\hline \multirow[t]{2}{*}{ CV $(\%)$} & 14,9 & 6,2 & 24,6 & 31,9 \\
\hline & \multicolumn{4}{|c|}{ Milho (subárea 2) } \\
\hline $0,8^{\#, \mathrm{a}}$ & $19,3 \pm 5,3$ & $1,8 \pm 1,7$ & $3,3 \pm 3,3$ & $2,3 \pm 2,9$ \\
\hline $0,8^{\#, \mathrm{~b}}$ & $18,0 \pm 5,6$ & $0,5 \pm 1,0$ & $0,8 \pm 0,5$ & $0,3 \pm 0,5$ \\
\hline $0,8^{\#, \mathrm{c}}$ & $16,0 \pm 4,5$ & $1,8 \pm 2,2$ & $2,0 \pm 2,0$ & $4,8 \pm 1,3$ \\
\hline $0,8^{\#, \mathrm{~d}}$ & $18,8 \pm 0,5$ & $2,0 \pm 1,4$ & $0,8 \pm 0,9$ & $0,8 \pm 0,5$ \\
\hline Teste F & ns & ns & ns & $*$ \\
\hline CV (\%) & 7,9 & 30,8 & 35,3 & 31,3 \\
\hline
\end{tabular}

*\# Irrigado com água de Tratamento $1\left(\mathrm{CEa}=0,8 \mathrm{dS} \mathrm{m}{ }^{-1}\right)$ em caráter suplementar, nas parcelas anteriormente irrigadas com as águas de 0,8; 2,2; 3,6 e $5,0 \mathrm{dS} \mathrm{m}^{-1}(\mathrm{a}, \mathrm{b}, \mathrm{c}, \mathrm{d}$, respectivamente); médias \pm desvio padrão; $\mathrm{n}=5 ; \mathrm{ns}$ - não significativo; * significativo a $5 \%$

Em termos percentuais, no entanto, a esporulação do gênero Glomus continuou sendo a mais importante, correspondendo a 74,6 e 79,3\% do total de esporos, nas subáreas 1 e 2, respectivamente. A predominância do gênero Glomus, nas duas subáreas estudadas, nas diferentes épocas (estações seca e chuvosa) e sob condições de elevada salinidade, confirma o amplo padrão de distribuição observado por outros autores na zona tropical, sendo um indicativo de que esse gênero apresenta alta capacidade adaptativa a faixas amplas de condições ambientais (SILVA JÚNIOR et al., 2004).

\section{Conclusões}

1. O aumento da salinidade da água de irrigação promoveu aumento do número total de esporos e do gênero Glomus, ao final dos cultivos da estação seca; 
2. O gênero Glomus respondeu por mais de $70 \%$ dos esporos totais encontrados, sendo que essa percentagem aumentou nos tratamentos com maior salinidade nos cultivos da estação seca;

3. Os maiores níveis de salinidade resultaram em redução da respiração basal do solo, no carbono da biomassa microbiana e no coeficiente metabólico microbiano $\left(\mathrm{qCO}_{2}\right)$, porém esses efeitos somente foram verificados na área cultivada com feijão-decorda;

4. Os dados não evidenciaram qualquer efeito negativo da salinidade residual sobre as variáveis microbiológicas avaliadas, em função da irrigação com água salina durante os cultivos da estação seca;

5. O número total de esporos, a respiração basal do solo e o carbono da biomassa microbiana variaram em função da época de coleta (estação seca e estação chuvosa) e da espécie cultivada na área (milho e feijão-de-corda).

\section{Referências}

ANDERSON, T. H.; DOMSCH, K. H. Application of ecophysiological quotients (qCO2) on microbial biomass from soils of different cropping history. Soil Biology and Biochemistry, v. 22, p. 251-255, 1990.

ANDERSON, T. H. Physiological analysis of microbial communities in soil, applications and limitation. In: RITZ, K.; DIGHTON, J.; GILLER, K. E. Beyond the Biomass. Wiley, Chichester, UK: British Soil Science Society, 1994. p. 67-76.

AYRES, R. S.; WESTCOT, D. W. A qualidade da água na agricultura. 2. ed. Campina Grande: UFPB, 1999. 153 p.

BARNARD, J. H.; RENSBURG, L. D. V.; BENNIE, A. T. P. Leaching irrigated saline sandy to sandy loam apedal soils with water of a constant salinity. Irrigation Science, v. 28, n. 02, p. 191-201, 2010.

BERNARDO, S.; MANTOVANI, E. C.; SOARES, A. A. Manual de Irrigação. 8. ed. Viçosa: UFV, 2008. 611 p.

CAPRONI, A. L. et al. Ocorrência de fungos micorrízicos arbusculares em áreas revegetadas após mineração de bauxita em Porto Trombetas, Pará. Pesquisa Agropecuária Brasileira, v. 38, n. 12, p. 1409-1418, 2003.

DOORENBOS, J.; KASSAN, A. H. Efeito da água no rendimento das culturas. 21. ed. Campina Grande: UFPB, 1994. 306 p.

FERNANDES, V. L. B. Recomendações de adubação e calagem para o Estado do Ceará. Fortaleza: UFC, 1993. 248 p.

GARCIA, I. V.; MENDOZA, R. E. Arbuscular mycorrhizal fungi and plant symbiosis in a saline-sodic soil. Mycorrhiza, v. 17, n. 03, p. 167-174, 2007.
GARCIA, G. O. et al. Alterações químicas de dois solos irrigados com água salina. Revista Ciência Agronômica, v. 39, n. 01, p. 7-18, 2008.

GERDEMANN, J. W.; NICHOLSON, T. H. Spore of mycorrhizal Endogene specie extracted from soil by wet sieving and decanting. Transactive Britanish Mycology Society, v. 46, p. $235-244,1963$.

ISLAM, K. R.; WEIL, R. R. Microwave irradiation of soil for measurement of microbial biomass carbon. Biology and Fertility of Soils, v. 27, n. 04, p. 408-416, 1998.

ISLAM, K. R.; WEIL, R. R. Land useeffectson soil quality in a tropical forest ecosystem of Bangladesh. Agriculture Ecosystem and Environmental, v. 79, n. 01, p. 9-16, 2000.

JAHROMI, F. et al. Influence of salinity on the in vitro development of Glomus intraradices and on the in vivo physiological and molecular responses of mycorrhizal lettuce plants. Microbial Ecology, v. 55, n. 01, p. 45-53, 2008.

JUNIPER, S.; ABBOTT, L. K. Vesicular-arbuscular mycorrizal and soil salinity. Mycorrhiza, v. 04, n. 02, p. 45-57, 1993.

JUNIPER, S.; ABBOTT, L. K. Soil salinity delays germination and limits growth of hyphae from propagules of arbuscular micorrhizal fungi. Micorrhiza, v. 16, n. 05, p. 371-379, 2006.

MEDEIROS, J. F. Qualidade da água de irrigação e evolução da salinidade nas propriedades assistidas pelo GAT, nos estados do RN, PB e CE. 1992. 137 f. Dissertação (Mestrado em Irrigação e Drenagem) Universidade Federal de Campina Grande, Campina Grande - PB.

MOREIA, F. M. S.; SIQUEIRA, J. O. Microbilogia e bioquímica do solo. 2. ed. Lavras: UFV, 2006. 729 p.

PEREIRA, S. V. et al. Atividade microbiana em solo do semi-árido sob cultivo de Atriplex nummularia. Pesquisa Agropecuária Brasileira, v. 39, n. 08, p. 757-762, 2004.

RHOADES, J. D.; KANDIAH, A.; MASHALI, A. M. Uso de águas salinas para a produção agrícola. Campina Grande: UFPB, 2000. 117 p.

RIBEIRO JÚNIR, J. I. Análises Estatísticas no SAEG..Viçosa: UFV, 2001. $301 \mathrm{p}$.

SAINT- ETIENNE, L. et al. Arbuscular mycorrhizal soil infectivity in stand of the wetland tree Pterocarpus officinales along a salinity gradient. Forest Ecology and Management, v. 232, n. 01/03, p. 86-89, 2006.

SANTOS, H. G. et al. Sistema brasileiro de classificação do solo. 2 ed. Rio de Janeiro: Embrapa Solos, 2006. 30 p.

SHENCK, C. N.; PÉREZ Y. Manual for the identification of VA mycorrhizal fungi. 3. ed. Gainesville: Synergistic Publications, 1990. 286 p.

SILVA, E. F.; ASSIS JÚNIOR, R. M.; SOUSA, J. I. G. Efeito da qualidade da água de irrigação sobre atributos hídricos de um neossolo. Revista Brasileira de Ciência do Solo, v. 29, n. 03, 389-396, 2005. 
SILVA JÚNIOR, M. et al. Hidrólise de diacetato de fluoresceína como biondicador da atividade microbiológica de um solo submetido a reflorestamento. Ciência Rural, v. 34. n. 05, p. 1493-1495, 2004.

SILVA JÚNIOR, J. M. T. et al. Efeitos de níveis de salinidade sobre a atividade microbiana de um Argissolo Amarelo incubado com diferentes adubos orgânicos. Revista Brasileira de Ciências Agrárias, v. 04, n. 04, p. 378-382, 2009.

SPARLLIN, G. P.; WEST, A. W. A direct extraction method to estimate soil microbial $\mathrm{C}$ : Calibration in situ using microbial respiration and ${ }^{14} \mathrm{C}$ labelet cells. Soil Biology and Biochemistre, v. 20, p. 337-343, 1988.

VANCE, E. D. et al. An extraction method for measuring soil microbial biomass carbon. Soil Biology Biochemistry, v. 19, n. 06, p. 703-707, 1987.
WICHERN, J.; ICHERN, W.; JOERGENSEN, R. G. Impact of salinity on soil microbial communities and the decomposition of maize in acidic soils. Geoderma, v. 137, n. 01, p. 100-108, 2006.

WILDE P. et al. Biodiversity of arbuscular mycorrhizal fungi in roots and soils of two salt marshes. Environmental Microbiology, v. 11, n. 06, p.1548-1561, 2009.

YANO-MELO, A. M. et al. Tolerance of mycorrhized banana (Musa sp. Cv. Pacovan) plantets to saline stress. Ecosystems and Environment, v. 95, p. 343-348, 2003.

YUAN, B. C. et al. Microbial biomass and activity in salt affected soils under arid conditions. Applied Soil Ecology, v. 35, n. 02, p. 319-328, 2007. 